\title{
Some Perspectives on Hypersensitivity to Coronary Stents
}

\author{
Valentin Chioncel (iD) ${ }^{1, *}$ \\ Catalina Liliana Andrei (iD ${ }^{1, *}$ \\ Radu Brezeanul,* \\ Crina Sinescu (D) ${ }^{1, *}$ \\ Anamaria Avram ${ }^{1, *}$ \\ Alin Laurentiu Tatu (D) ${ }^{2, *}$ \\ 'Department of Cardio-Thoracic \\ Pathology, Faculty of Medicine, "Carol \\ Davila" University of Medicine and \\ Pharmacy, Bucharest, 050474, Romania; \\ ${ }^{2}$ Medical and Pharmaceutical Research \\ Unit/Competitive, Interdisciplinary \\ Research Integrated Platform "Dunărea \\ de Jos", ReForm-UDJG, Research Centre \\ in the Field of Medical and Pharmaceutical \\ Sciences, Faculty of Medicine and \\ Pharmacy, Clinical Medical Department, \\ "Dunărea de Jos" University of Galati, \\ Galati, 8000I0, Romania
}

*These authors contributed equally to this work
Correspondence: Valentin Chioncel Department of Cardio-Thoracic Pathology, Faculty of Medicine, "Carol Davila" University of Medicine and Pharmacy, Bucharest, 050474, Romania Email chioncelv@yahoo.com

\begin{abstract}
The development of coronary stents has represented a revolution in the treatment of coronary heart disease. Beyond their many advantages, stents also have their limitations and complications. Allergic reactions to coronary stents are more common than acknowledged. These stented patients are exposed to foreign substances inserted in direct contact with the coronary intima. Hypersensitivity to stent components and drugs prescribed after stent insertion together with any environmental exposure seem to contribute to these adverse reactions. Patients can present to the hospital with a wide range of symptoms and multiple complications, the most important ones being instent restenosis and stent thrombosis. Although not very common (and not always easy to identify), allergic reactions after coronary or peripheral stents should be taken into account. Careful selection of patients (for elective stent implantation) depending on the propensity to allergies, although hard to achieve, represents a key factor in reducing the number of these complications.
\end{abstract}

Keywords: stents, allergy, restenosis, thrombosis, Kounis syndrome

\section{Introduction}

Cardiovascular diseases are disorders that involve the heart or blood vessels and are considered to be the leading cause of morbidity and mortality worldwide. ${ }^{1}$ Since the first balloon dilations in 1977, coronary angioplasty has become the main therapy for coronary heart disease. ${ }^{2}$

Main drawbacks arising from balloon angioplasty - elastic recoil of the vessel and coronary dissections - have been diminished by stent implantation. The first coronary stent implantation in a human being in 1984 represented a huge step forward in treating these patients.

Over 2 million stents are being implanted annually worldwide, the majority of them pharmacologically active. ${ }^{3}$ Although this is a revolutionary step in treating coronary patients, stents - just like any other therapy - are also prone to complications or side effects.

During percutaneous coronary interventions (PCI), an expandable coronary stent is placed inside the culprit artery and arterial injury is an inevitable consequence of all interventional procedures; this injury initiates a cascade of cellular and molecular events.

Stents are usually metal made, nickel, cobalt and chromium being the most common. Both cutaneous and extracutaneous allergic reactions, together with delayed-type hypersensitivity due to chronic metal exposure are well known and documented in the literature (stent thrombosis, instent restenosis, inflammation, pain). 
Despite repeated attempts and research to further understand this pathology, the association between metal sensitivity and allergic response to intravascular stents remain to be discovered.

This review can provide an update on the current information in this domain and can be very useful for doctors who come across and manage patients with these conditions.

\section{Main Issues}

The main complications of stent implantation are represented by instent restenosis and stent thrombosis. ${ }^{4,5}$

Coronary restenosis is the consequence of intimal hyperplasia as a response to injury from balloon/stent. This was a major challenge which was greatly reduced after the appearance of stents impregnated with active substances, the so-called drug eluting stents (DES). The first published studies with DES (RAVEL, SIRIUS) showed a much lower rate of restenosis compared to bare metal stents. ${ }^{6,7}$ Subsequently, numerous researches have confirmed the obvious advantages of DES. ${ }^{8-10}$

Nowadays, the incidence of instent restenosis in all invasive coronary procedures is around $10-15 \%$ and the main treatment is usually the insertion of another stent or Drug Eluting Balloon Angioplasty (DEBA). ${ }^{11}$

Stent thrombosis is a rare but sometimes critical PCI complication that can lead to myocardial infarction or death. ${ }^{12}$ The incidence of stent thrombosis ranges between $0.5 \%$ and $2 \%$ and may occur despite recent progress in antiplatelet therapy and technique. ${ }^{13-15}$
The question has sometimes been raised whether these main complications (restenosis and stent thrombosis) may be related to allergies or hypersensitivity to the stent materials. Therefore, current research is focused on the safety of coronary stents.

DES hypersensitivity reactions represent an increasing challenge and may be the result of eluted drugs or intrinsic metals and stent polymers - see Figure 1. Sometimes antiplatelet medication may be involved so the causality relationship is not very easy to establish.

During the last 30 years there has been a growing concern within the medical and patient communities about possible allergic (hypersensitivity) reactions to foreign materials implanted in the body.

One of the main question is whether hypersensitivity reactions to materials from intracoronary artery stents could be associated with instent restenosis and thrombosis.

\section{Instent Restenosis}

Bare metal stents are made from stainless steel, which is a steel with added nickel and chromium, nickel being one of the most common causes of allergic contact dermatitis. DES contain, in addition to metal frame, a polymer coating (permanent or biodegradable) in which the antiproliferative drug is printed.

Conceptually, any stent component may induce immune-mediated thrombosis or restenosis in hypersensitive patients. Cases about such detrimental response of antiproliferative drugs and polymer coatings of drug-

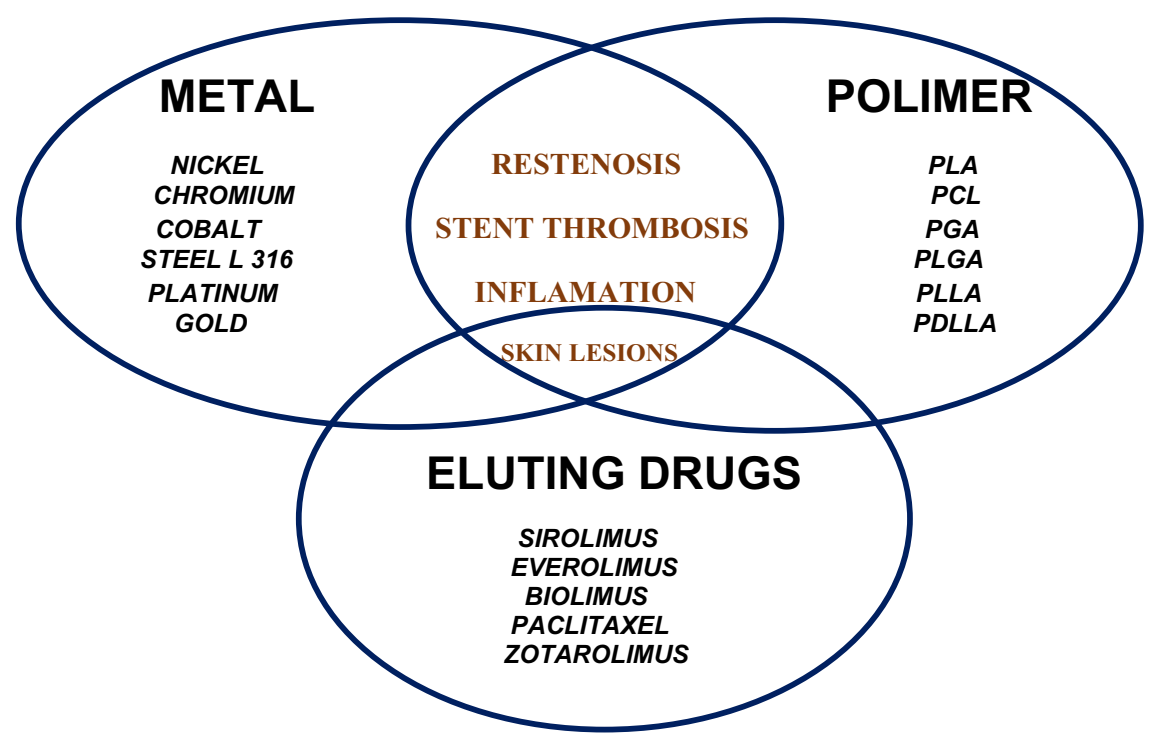

Figure I Hypersensitivity side effects of stents. 
eluting stents have been reported, ${ }^{16}$ but it remains uncertain whether stent metal components may induce local implant failure when used in patients with metal allergy.

Case reports of nickel allergies have been published since 1980 , with estimates of a $10 \%$ overall incidence in the general population. Because it is thought that piercing sensitization is the cause in the majority of cases, incidence in women is higher, between $14 \%$ and $20 \%{ }^{17}$

Most of the reported cases of nickel allergy manifest as a common contact dermatitis, but patients with nickelcontaining medical implants who develop nickel allergy typically have a more pronounced systemic response, which frequently include diffuse eczematous rash with no or poor response to corticosteroids.

Hypersensitive skin reactions are more often described to nickel, but allergic signs or symptoms can also occur in other metals such as cobalt, chromium, molybdenum, and gold. $^{18}$

Since 1995, coronary stents used worldwide have been designed using $316 \mathrm{~L}$ stainless steel, cobalt-chromium alloy or platinum-chromium alloy platforms and recently - platinum-chromate (18-20\%), and molybdenum (2.7-9.7\%).

After the implantation of a stent that contains nickel, the metal is steadily released into the systemic circulation, promoting the expression of intercellular adhesion molecule-1 (ICAM-1) on endothelial cells, which plays an important role in the recruitment of inflammatory cells from the bloodstream. ${ }^{19}$ In allergic cases, the release of metal ions after skin contact induces a type IV hypersensitivity reaction mediated by allergen-specific $\mathrm{T}$ lymphocytes, manifesting as a red pruritic rash with areas of vesiculation and triggering excessive immunologic response. ${ }^{20,21}$

Despite massive technological advance in production of stents, instent restenosis remains a major clinical problem and the factors predisposing to restenosis are still largely unknown.

Restenosis usually appears within 3-6 months after intervention but may also occur later. ${ }^{22-24}$ It is often defined as target lesion revascularization and the incidence in traditional stents is usually reported between $10 \%$ and $30 \%$. $^{24,25}$

Contact allergy to metal ions eluted from the stainless steel stents, mostly nickel, chromate and molybdenum, has been suggested to be a factor that contributes to instent restenosis. $^{26}$

In this regard, some clinical studies have suggested a higher risk of restenosis in patients who were found to be patch-test positive for metal allergy after stent placement. $^{27,28}$

However, the results of the studies are contradictory and there is still no firm conclusion in this area.

In the early 2000s, despite limited data, Food and Drug Administration warns against stent implantation in patients with a history of metal allergy and initiated Research on Adverse Drug/Device events And Reports (RADAR) project who reviews potentially causal associations between therapeutic agents and adverse events. ${ }^{29}$

In October 2003, an FDA advisory described 50 hypersensitivity cases after CYPHER stent implantation ${ }^{30}$ with symptoms like rash, dyspnea, hives, itching and fevers, but one month later (November 2003), a follow-up advisory indicated that almost all of the hypersensitivity reactions were caused by standard drug therapy associated with stent implantation. $^{31}$

RADAR investigators assessed all available cases for the possibility that DES components may be a cause of hypersensitivity reactions and this was the first study that assessed hypersensitivity-like reactions that occurred after DES placement.

Within 2 weeks after stent implantation, $85 \%$ of these patients developed symptoms, including rash (78\%), itching (27\%), hives (23\%), fever (13\%) and anaphylaxis (6\%). Symptoms persisted $>30$ days in $50 \%$ of patients and were classified as serious in $95 \%$ of cases, $34 \%$ needed emergent intervention and 18\% hospitalization.

In only 17 of 262 cases of hypersensitivity cases reported to the FDA, the stent itself appears to be the most probable cause of hypersensitivity signs.

According to specific WHO criteria (which classify causal associations as certain, probable, possible, or unlikely), only one event was certainly caused by a DES, nine were probably caused by DES, and an additional seven cases of probable or certain hypersensitivity caused by a DES were identified later. ${ }^{32}$ In two cases, allergy signs were certainly caused by clopidogrel. In four patients with focal hypersensitivity, the necroptic exam found instent eosinophilic infiltrates and poor intimal healing as late as 18 months after implantation, possibly caused by DES.

RADAR study concluded that both metallic and nonmetallic components of DES could induce hypersensitivity. Regarding the drugs impregnated in the stents, Sirolimus is an unlikely cause of hypersensitivity because it typically reduces eosinophilic infiltration and histamine release and has been associated with low rates of 
hypersensitivity, ${ }^{33}$ but the incidence of allergic reactions to Paclitaxel itself is not known. ${ }^{34}$

The polymer matrix can fragment and expose metal structure, ${ }^{35}$ raising concern that nickel, chrome and molybdenum may induce hypersensitivity, so polymer coating could cause late and persistent allergic reactions. ${ }^{36}$

In conclusion, study findings suggest that local and systemic hypersensitivity can develop in response to implantation of DES in coronary arteries. But because clinical trials with thousands of patients have not reported increased mortality with DES compared to bare-metal stents, ${ }^{37,38}$ the incidence of fatal hypersensitivity events due to DES is likely to be very low.

The relationship between metal allergic reaction and development of instent restenosis in patients treated with $316 \mathrm{~L}$ stainless steel stents has been investigated before. In general, prior clinical studies have suggested an increased propensity for recurrent restenosis in patients with metal hypersensitivity.

Köster et $\mathrm{al}^{26}$ showed that a delayed hypersensitivity reaction to nickel and molybdenum might be a part of the inflammatory process and one of the triggering factors of restenosis. His group performed patch testing for metal allergies on 131 patients undergoing repeated angiography for suspected restenosis approximately 6 months after bare metal stenting. Of these, all 10 patients who had positive patch reactions were found to have instent restenosis. In contrast, only $79(65 \%)$ of the remaining 121 patients (who were patch-negative) had restenosis. So the statistically significant difference $(\mathrm{p}=0.03)$ suggests that the allergic reaction to implanted metal was a trigger for restenosis.

In the same pattern, Iijima et $\mathrm{al}^{27}$ found that positive patch test was a significant predictor of recurrent restenosis in patients treated with $316 \mathrm{~L}$ stainless steel stents $(p=0.02)$.

Another research from Aliağaoğlu et $\mathrm{al}^{39}$ enrolled 256 patients who had received cobalt chromium coronary stent. Coronary angiography and patch testing were performed independently in 61 cases and instent restenosis was found in 31 of them. According to the patch test results, 7 of 31 patients (23\%) from the restenosis group had nickel contact allergy, while none of the 30 patients $(0 \%)$ from the non-restenosis group had nickel allergy and the difference was found to be statistically significant $(p \sim 0.006)$. Therefore, the results of the study showed a correlation between nickel allergy and instent restenosis in patients treated with cobalt chromium stents.
Specific concern was raised with regard to gold-plated stents that appeared to induce systemic or focal hypersensitivity.

Svedman et al ${ }^{28,40,41}$ investigated any possible relationship between contact allergy to stent material, especially nickel and gold, and coronary artery restenosis. They found that the rates of restenosis were higher in goldallergic versus nonallergic patients. Such stents are no longer in use.

In another study, Saito et al looked for a correlation between patch positivity and restenosis in stented patients. ${ }^{42}$ Thus, patch positivity was significantly more frequent ( $p \sim 0.02$ ) in a group with recurrent restenosis $(9 / 23)$ compared with the nonrecurrence group (5/42), leading the authors to suggest that the tissue reaction to the metal component of $316 \mathrm{~L}$, especially nickel, may play an important role in chronic refractory restenosis.

Coronary stents are not the only ones that can determine hypersensitivity. There are also cases of peripheral stents (made of Nitinol, with high nickel content) described in the literature, which led to allergic reactions. ${ }^{43}$

There are some reported cases of significant stent allergy, which needed removal of the nickel-containing medical device (which may or may not be feasible).

In another example - a 70-year-old female developed generalized pruritus and rash, which appeared shortly after implantation of an iliac metallic stent; the only way to relieve the symptoms was the removal of the stent. ${ }^{44}$

Similarly, there have been reports of severe systemic symptoms occurring after the placement of metallic patent foramen ovale closure devices, symptoms who had resolved with the removal of the device. ${ }^{45}$

In another study on 47 patients who underwent patent foramen ovale closure using an Amplatzer device (50\% nickel), 5 patients (of the 8 subsequently identified as nickel-allergic by patch testing) reported an increase in the frequency of migraine headaches, chest pain, and palpitations after device placement, significantly more frequent than reported by nonallergic control subjects. ${ }^{46}$ However, there were no implant failure or detectable differences in device performance in the allergy group compared with control subjects.

On the other hand, Norgaz et al did not found any difference between nickel allergy in restenosis patients vs non-restenosis cases. ${ }^{47}$ Therefore, the study did not support the relationship between nickel allergy and the development of restenosis in patients having stainless steel stents. 
Another small study from Denmark identified 17 patients who had been stented in the recent past and developed dermatitis as an allergy to nickel or chromium. ${ }^{48}$ Only 2 patients had to repeat coronary intervention, statistically similar to nonallergic patients.

In Slodownik analysis 99 patients were followed - 70 patients had patent stents at the second angiogram (patent stent group) and 29 were found to have instent restenosis (restenosis group) ${ }^{49}$ Twenty-eight (28.3\%) patients were found to have an allergy to at least one metal. There was no significant difference in the prevalence of metal allergy between the patent stent group and the restenosis group (28.6 and $27.6 \%$, respectively; $p=0.921$ ). Their results do not sustain the theory that metal allergy plays a role in the pathogenesis of instent restenosis.

Another retrospective study also suggests that coronary stent implantation in patients with a history of metal allergy is not associated with adverse early or late cardiovascular outcomes. Romero-Brufau et al compared 29 metal-allergic patients who underwent coronary stent implantation to a nonallergic group (250 patients) matched for demographics and a propensity for allergy to metal. ${ }^{50}$ There were no differences in the number of segments treated, stents placed, and frequency of drug-eluting stent usage. Regarding in-hospital death, myocardial infarction, 30-day mortality and MI, 4-year mortality, target lesion revascularization (TLR) and death/MI/TLR no statistical differences were found.

Considering all these, clinical outcomes after stent placement in patients with a history of metal allergy remains unclear and mechanisms remain incompletely understood.

Hypersensitivity reactions can be caused not only by the metal matrix of the stent, but also by the polymeric coating (in the case of DES).

Structure of DES includes a polymer matrix, which allow the delivery of antiproliferative drugs to inhibit vascular smooth muscle cell growth.

First-generation DES was based on biostable polymeric drug carriers, such as poly(ethylene-co-vinyl acetate) (PEVA), poly(n-butyl methacrylate) (PBMA), and poly (styrene-b-isobutylene-b-styrene) block polymers (SIBS). Hypersensitivity reactions have been reported ${ }^{51,52}$ and the persistence of polymer coatings after drug release, causing poor reendothelialization and favoring late stent thrombosis. $^{53}$

Therefore, second-generation DES was developed with biodegradable polymers able to degrade (in a period of 6
24 months) once its function is fulfilled. This resulted in a decrease in late and very late stent-thrombosis and also hypersensitivity reactions.

Typical representatives of biodegradable polymers (who degrade physiologically by hydrolysis) are polyhydroxycarboxylic acids, like poly-glycolide (PGA), polylactides (PLA), and poly-caprolactone (PCL). PLA has been intensely tested as temporary stent material in cardiology due to its long track records of in vivo biocompatibility. ${ }^{54}$ Some polymers (considered to be more biocompatible), such as synthetic PLA, need years to degrade and therefore carry a risk of late and very late stent-thrombosis. In addition PGA, may generate fragments potentially leading to emboli. ${ }^{55}$ Therefore, bioresorbable polymers are not without risks and are a work in progress. ${ }^{56}$

Second- and third-generation DES use biomimetic polymers (such as phosphorylcholine - PC, polyvinylidene fluoride-hexafluoropropylene - PVDF-HFP, or the BioLinx polymer), which do not interfere with stent reendothelialization. ${ }^{57}$

Recently, biodegradable polymers (such as PLA and polylactide-co-glycolide - PLGA), and polymer-free DES were extensively studied to optimize their biocompatibility. ${ }^{58}$

However, several studies report that patients treated with polymer-free stents show similar clinical outcomes to those treated with durable polymer DES in terms of mortality, stent thrombosis, and long-term efficacy. ${ }^{59}$

The idea of a fully biodegradable scaffold may reduce the requirements for a long-term dual antiplatelet therapy and facilitate the return of vessel vasomotion. ${ }^{60}$ Clinically approved scaffolds are mostly based on PLA (a polyLlactide - PLLA and a polyD,L-lactide - PDLLA). Currently, there are some drawbacks regarding aggressive inflammatory reactions during polymer erosion leading to instent restenosis. $^{61}$

Therefore, the future tasks for the development of biomaterials used for medical applications are not only to adapt stent designs, but to find and promote biomaterials with antithrombotic and anti-inflammatory properties.

\section{Stent Thrombosis/Kounis Syndrome}

Stent thrombosis is a dramatic complication of coronary stenting, often presented as acute myocardial infarction or even sudden death. Based on the stent implantation moment, stent thrombosis can be classified as early ( 0 30 days post stent implantation); late ( $>30$ days); very late 
(>12 months). Late and very late stent thrombosis are associated with a variety of causes, such as poor endothelialization, inflammation, delayed healing, neoatherosclerosis and local hypersensitivity reaction. ${ }^{62}$ Cases of stent thrombosis due to stent allergy ${ }^{27,38}$ have been reported even 2-3 years after stent implantation because nickel sensitization may persist for many years. ${ }^{63}$

Stent thrombosis is the result of serial adhesion, activation and aggregation of platelets. Platelet aggregation is the result of GP IIb/IIIa receptor binding with fibrinogen and interaction with VWF. Thrombin converts fibrinogen to fibrin, which serves as a stable matrix for the creation of thrombus. Therefore, receptors for hypersensitivity mediators are also participating in platelet activation and these mediators are derived from the allergic unit of eosinophils and mast cells. ${ }^{64}$ This can explain why patients can develop stent thrombosis during an allergic episode.

On the other hand, local endothelial inflammation (intercellular adhesion molecule-1 that recruits inflammatory cells from the bloodstream ${ }^{65}$ ) and excessive immune response (a type IV hypersensitivity reaction mediated by allergen-specific $\mathrm{T}$ lymphocytes ${ }^{15}$ ) play important roles in the occurrence of stent thrombosis.

Chronic inflammation and endothelial dysfunction induce neoatherosclerosis on the long term inside both bare metal and drug-eluting stents, and the disruption of neoatherosclerotic plaques plays an important role in the occurrence of late, and especially, very late stent thrombosis. ${ }^{66}$ Since inflammation is one of the main causes of stent thrombosis, ${ }^{67}$ the systemic administration of anti-inflammatory or immunosuppressive therapy (oral steroids after PCI when a metal allergy is confirmed), in addition to double antiplatelet therapy, might be beneficial in suppressing the vascular inflammation and lowering the rates of stent thrombosis. ${ }^{68-70}$

Konishi et al reported a case with recurrent stent thrombosis in a patient with proved stent allergy who can benefit of systemic corticotherapy. ${ }^{71}$ Besides antiplatelet therapy, low doses of steroids might confer clinical benefits and lower the incidence of stent thrombosis due to their anti-inflammatory properties.

In a post-mortem study, eosinophilic infiltrations were observed at the site of the stent in patients with stent thrombosis associated with stent allergies. ${ }^{51,72}$

Therefore, patients who develop repetitive stent thrombosis after stent implantation should undergo patch testing in search of metal allergy.

Recent studies have reported a low incidence of stent thrombosis after implantation of bioresorbable vascular scaffolds where the risk is markedly decreased after the elution of the anti-proliferative drug and the resorption of the scaffold. This evidence may be very important in patients presenting with stent allergy undergoing PCI who might benefit from these devices. ${ }^{73}$

Another situation in which coronary heart disease interferes with allergic pathogenic processes is Kounis syndrome.

Kounis syndrome is an acute coronary syndrome, secondary to an allergic reaction. In these cases, cytokine release might precipitate coronary spasm, plaque rupture, or stent thrombosis.

There are 3 types described - type III (about 5\% of Kounis syndrome cases) includes patients with coronary artery stent thrombosis as a result of an allergic reaction, with histologically demonstrated presence of mast cells and eosinophils from the aspirated thrombus. ${ }^{74,75}$

Multiple cases of type III Kounis syndrome have been reported in the literature.

Tzanis et al described a curious case of early stent thrombosis (4 days after implantation) following an allergic reaction to food consumption in a 70-year-old man. ${ }^{76}$

In another report, Tripolino et al described the case of a 47-year-old man with acute stent thrombosis, as a consequence of allergic reaction to contrast media. ${ }^{77}$ After $30 \mathrm{~min}$ from the end of angioplasty (LAD stenting), the patient experienced nausea, sweating, chest pain, generalized itching followed by the appearance of cutaneous erythema. ECG revealed significant ST segment elevation in V2-V5 and immediate coronary angiography showed complete stent thrombosis.

The treatment included hydrocortisone, chlorpheniramine, oxygen, saline infusion and angioplasty was repeated with good result.

Michas et al reported a case of ST elevation myocardial infarction due to stent thrombosis in the setting of an allergic reaction associated with mushroom consumption. $^{78}$

Kounis syndrome may be another example of the link between stent implantation and allergic reactions, sometimes resulting in serious complications such as restenosis and stent thrombosis - see Table 1.

A special care should be provided for patients with multiple autoimmune syndromes and stent implantation. ${ }^{79}$

In diabetic patients, atherosclerosis is more persistent and aggressive than in non-diabetic patients and cardiovascular risk is particularly high; therefore, ischaemic heart disease and stroke cases are more than double in 
Table I Studies or Case Reports About Stents' Side Effects

\begin{tabular}{|c|c|c|}
\hline \multicolumn{3}{|l|}{ Instent Restenosis } \\
\hline Köster et $\mathrm{al}^{26}(2000)$ & $100 \%$ restenosis (patch-positive) vs $65 \%$ restenosis (patch-negative) & $p=0.03$ \\
\hline lijima et $\mathrm{al}^{27}(2005)$ & Patch test - significant predictor of restenosis & $p=0.02$ \\
\hline Aliagaoglu et $\mathrm{al}^{39}(2012)$ & $23 \%$ restenosis (patch-positive) vs $0 \%$ restenosis (patch-negative) & $p=0.006$ \\
\hline Svedman et $\mathrm{al}^{28,40,41}(2005,2006,2009)$ & Restenosis rate higher in gold stents & \\
\hline Saito et al ${ }^{42}(2009)$ & Restenosis group: $39 \%$ patch-positive vs II\% patch-negative & $p=0.02$ \\
\hline Norgaz et al ${ }^{47}(2005)$ & No difference in spite of restenosis & \\
\hline Thyssen et al ${ }^{48}(20 \mathrm{II})$ & Similar rate of restenosis & \\
\hline Slodovnik et $\mathrm{al}^{49}(2018)$ & No restenosis difference between patch-positive and patch-negative & $P=0.921$ \\
\hline Romero-Bruffau et $\mathrm{al}^{50}(2012)$ & No difference of main endpoints (metal allergy vs no metal allergy) & \\
\hline \multicolumn{3}{|l|}{ Stent Thrombosis } \\
\hline Konishi et al ${ }^{71}(2015)$ & Reccurent stent thrombosis in patient with metal allergy & \\
\hline Nebeker $^{52}(2006)$ & Eosinophilic infiltrates in patients with stent thrombosis (post-mortem study) & \\
\hline Stone $^{38}(2004)$ & Stent thrombosis due to stent allergy & \\
\hline \multicolumn{3}{|l|}{ Kounis Syndrome } \\
\hline Tzanis $^{76}(2017)$ & Early stent thrombosis after allergic reaction & \\
\hline Tripolino $^{77}$ (2019) & Acute stent thrombosis after allergic reaction to contrast media & \\
\hline Michas $^{78}(2017)$ & Stent thrombosis after mushroom allergy & \\
\hline \multicolumn{3}{|l|}{ Skin Reactions } \\
\hline $\operatorname{RADAR}^{29}(2003)$ & 17 from 262 patients: rash, itching, hives, fever, anaphylaxis & \\
\hline Guntani et al ${ }^{44}(2020)$ & Generalized pruritus after iliac metallic stent & \\
\hline
\end{tabular}

diabetic than in the non-diabetic population. ${ }^{80}$ This is the reason why the treatment of diabetic patients with coronary heart disease must be much more intensive; drugeluting stents (DES) are thus a big step forward in the field of interventional therapies in these patients.

However, both stent thrombosis and instent restenosis are more common in patients with diabetes. Restenosis after stenting, caused by neointimal hyperplasia, remains a major concern, especially for the diabetic population. In a metaanalysis of six studies, the average restenosis rates among patients with diabetes were $50 \%$ higher than in nondiabetics. ${ }^{81}$

Diabetes is also a major risk factor for stent thrombosis. In one study, the rate of stent thrombosis was 1.8 times higher in diabetic than in nondiabetic patients $(3.2 \%$ vs $1.7 \%) .{ }^{82}$

These are some of the reasons why coronary artery bypass grafting is often preferred to angioplasty in diabetic patients. However, there is no strong evidence of a higher risk of hypersensitivity to stents in diabetic patients than in non-diabetic patients.

On the other hand, experts do not consider the risk of allergies secondary to stent implant to be a major issue.
Morton Kern responded with a triple NO for this issue of coronary stents. NO, I do not test for nickel allergy. NO, I do not treat patients for nickel allergy. And, finally, NO, I do not pick stents based on fear of allergy. ${ }^{83}$

Dr. Greg Stone from Columbia University, NYC, also commented, "Most studies have not found a firm relationship between nickel allergy and restenosis".

So despite the theoretical evidence and reported cases regarding the relationship between the stent implant and subsequent allergic reactions, we cannot currently know the magnitude of this problem.

Despite the fact that it is a life-saving therapy, coronary stents can occasionally cause serious adverse events for those patients. The metallic matrix, polymer coating, eluted drugs, antiplatelets and other drugs (which the stented patients are taking) act as strong antigenic complex able to induce an allergic reaction and some complications like instent restenosis and stent thrombosis. ${ }^{84,85}$

New solid trials and evidence based guidelines for risk assessment, diagnostic testing and treatment are needed. Similar reactions may occur after other types of surgery with or without inoculation of materials considered non-self. 


\section{Conclusions}

Although restenosis and stent thrombosis are regarded as multifactorial complications, procedural, clinical and angiographic variables have also been incriminated.

Specialists must educate colleagues about these potential complications. Patients should be questioned regarding their allergic history and advised about increased risks prior to the placement of intracoronary stents.

Although there are voices that minimize this connection, the problem should not be neglected.

At least in stented patients suffering from recurrent restenosis or stent thrombosis, hypersensitivity to stent components probably plays an important role and should be a major concern. It remains to be proved whether in these cases anti-inflammatory or immunosuppressive therapy (on top of double antiplatelet medication) may be useful to limit these side effects.

\section{Data Sharing Statement}

All information is documented by relevant references.

\section{Author Contributions}

All authors made a significant contribution to the work reported, whether that is in the conception, study design, execution, acquisition of data, analysis and interpretation, or in all these areas; took part in drafting, revising or critically reviewing the article; gave final approval of the version to be published; have agreed on the journal to which the article has been submitted; and agreed to be accountable for all aspects of the work.

\section{Funding}

No funding was received.

\section{Disclosure}

The authors declare that they have no competing interests.

\section{References}

1. Krenning van Luyn GMJ, Harmsen MC. Endothelial progenitor cell-based neovascularization: implications for therapy. Trends $\mathrm{Mol}$ Med. 2009;15(4):180-189.

2. Liu T, Liu S, Zhang K, Chen J, Huang N. Endothelialization of implanted cardiovascular biomaterial surfaces: the development from in vitro to in vivo. $J$ Biomed Mater Res A. 2014;102 (10):3754-3772.

3. Lee JH, Kim ED, Jun EJ, Yoo HS, Lee JW. Analysis of trends and prospects regarding stents for human blood vessels. Biomaterials Research. 2018;22:8.
4. Wenaweser P, Rey C, Eberli FR, et al. Stent thrombosis following bare-metal stent implantation: success of emergency percutaneous coronary intervention and predictors of adverse outcome. Eur Heart J. 2005;26(12):1180-1187.

5. Windecker S, Meier B. Late coronary stent thrombosis. Circulation. 2007;116(17):1952-1965.

6. Morice MC, Serruys PW, Fajadet J, et al. RAVEL study group randomized study with the sirolimus-coated bx velocity balloon-expandable stent in the treatment of patients with de novo native coronary artery lesions a randomized comparison of a sirolimus-eluting stent with a standard stent for coronary revascularization. $N$ Engl J Med. 2002;346(23):1773-1780.

7. Moses J, Leon M, Popma J, et al. For the SIRIUS Investigators Sirolimus-eluting stents versus standard stents in patients with stenosis in a native coronary artery. $N$ Engl $J$ Med. 2003;349:1315-1323

8. Mohan S, Dhall A. A comparative study of restenosis rates in bare metal and drug-eluting stents. Int J Angiol. 2010;19(2):e66-e72. doi:10.1055/s-0031-1278368,

9. Auer J, Leitner A, Berent R, et al. Long-term outcomes following coronary drug-eluting- and bare-metal-stent implantation. Atherosclerosis. 2010;210(2):503-509. doi:10.1016/j.2010

10. Buccheri D, Piraino D, Andolina G, Cortese B. Understanding and managing in-stent restenosis: a review of clinical data, from pathogenesis to treatment. $J$ Thorac Dis. 2016;8(10):E1150-E1162. doi: $10.21037 /$ jtd.2016

11. Mohananey D, Saucedo J, Stone GW, et al. Trends and outcomes of restenosis after coronary stent implantation in the United States. $J$ Am Coll Cardiol. 2020;76(13):1521-1531.

12. Mauri L, Hsieh WH, Massaro JM, Ho KK, D'Agostino R, Cutlip DE. Stent thrombosis in randomized clinical trials of drug-eluting stents. N Engl J Med. 2007;356:1020-1029.

13. Jensen LO, Maeng M, Kaltoft A, et al. Stent thrombosis, myocardial infarction, and death after drug-eluting and bare-metal stent coronary interventions. J Am Coll Cardiol. 2007;50:463-470.

14. Brener SJ, Cristea E, Kirtane AJ, et al. Intra-procedural stent thrombosis: a new risk factor for adverse outcomes in patients undergoing percutaneous coronary intervention for acute coronary syndromes. JACC Cardiovasc Interv. 2013;6(1):36-43.

15. Généreux P, Stone GW, Harrington RA; CHAMPION PHOENIX Investigators, et al.. Impact of intraprocedural stent thrombosis during percutaneous coronary intervention: insights from the CHAMPION PHOENIX trial (Clinical trial comparing cangrelor to clopidogrel standard of care therapy in subjects who require percutaneous coronary intervention). J Am Coll Cardiol. 2014;63 (7):619.

16. Chen JP, Hou D, Pendyala L, Goudevenos JA, Kounis NG. Drug-eluting stent thrombosis: the Kounis hypersensitivity-associated acute coronary syndrome revisited. $J \mathrm{Am}$ Coll Cardiol Cardiovasc Interv. 2009;2:583-593.

17. Basko-Plluska JL, Thyssen JP, Schalock PC. Cutaneous and systemic hypersensitivity reactions to metallic implants. Dermatitis. 2011;22:65-79.

18. Nielsen NH, Linneberg A, Menne T, et al. Incidence of allergic contact sensitization in Danish adults between 1990 and 1998; the Copenhagen Allergy Study, Denmark. Br J Dermatol. 2002;147:487-492.

19. Wataha JC, O'Dell NL, Singh BB, Whitford GM, Lockwood PE. Relating nickel-induced tissue inflammation to nickel release in vivo. J Biomed Mater Res. 2001;58:537-544.

20. Thomas P, Summer B, Sander CA, Przybilla B, Thomas M, Naumann T. Intolerance of osteosynthesis material: evidence of dichromate contact allergy with concomitant oligoclonal T-cell infiltrate and TH1-type cytokine expression in the peri-implantar tissue. Allergy. 2000;55:969-972. 
21. Kornowski R, Hong MK, Tio FO, Bramwell O, Wu H, Leon MB. Instent restenosis: contributions of inflammatory responses and arterial injury to neointimal hyperplasia. $J \mathrm{Am}$ Coll Cardiol. 1998;31:224-230.

22. Beyar R. Novel approaches to reduce restenosis. Ann N Y Acad Sci. 2004; 1015:367-378.

23. Radke PW, Kaiser A, Frost C, Sigwart H. Outcome after treatment of coronary in-stent restenosis: results from a systematic review using meta-analysis techniques. Eur Heart J. 2003;24:266-273.

24. Cutlip DE, Chauhan MS, Baim DS, et al. Clinical restenosis after coronary stenting: perspectives from multicenter clinical trials. $\mathrm{J} \mathrm{Am}$ Coll Cardiol. 2002;18:2082-2089.

25. Schiele TM, Krotz F, Klauss V. Vascular restenosis striving for therapy. Expert Opin Pharmacother. 2004;5:2221-2232.

26. Köster R, Vieluf D, Kiehn M, et al. Nickel and molybdenum contact allergies in patients with coronary in-stent restenosis. Lancet. 2000;356:1895-1897.

27. Iijima R, Ikari Y, Amiya E, et al. The impact of metallic allergy on stent implantation: metal allergy and recurrence of in-stent restenosis. Int J Cardiol. 2005;104:319-325.

28. Svedman C, Ekqvist S, Moller H, et al. A correlation found between contact allergy to stent material and restenosis of the coronary arteries. Contact Dermatitis. 2009;60:158-164.

29. Bennett CL, Nebeker JR, Lyons EA, et al. The Research on Adverse Drug Events and Reports (RADAR) project. JAMA 2005;293:2131-2140.

30. Information for Physicians on Sub-Acute Thromboses (SAT) and Hypersensitivity Reactions with Use of the Cordis CYPHER Coronary Stent. FDA Public Health Web Notification. 1st ed. Rockville, MD: Food and Drug Administration; 2003.

31. Updated Information for Physicians on Sub-acute Thromboses (SAT) and Hypersensitivity Reactions with Use of the Cordis CYPHER Sirolimus-eluting Coronary Stent. FDA Public Health Web Notification. 1st ed. Rockville, MD: Food and Drug Administration; 2003.

32. Nebeker JR, Barach P, Samore MH. Clarifying adverse drug events: a clinician's guide to terminology, documentation, and reporting. Ann Intern Med. 2004;140:795-801.

33. Mosby's Drug Consult 2004 - The Comprehensive Reference for Generic and Brand Name Drugs. St. Louis, MO: Elsevier Inc.; 2004.

34. Rowinsky EK, Donehower RC. Paclitaxel (Taxol). $N$ Engl J Med. 1995;332:1004-1014.

35. Virmani R, Guagliumi G, Farb A, et al. Localized hypersensitivity and late coronary thrombosis secondary to a sirolimus-eluting stent: should we be cautious? Circulation. 2004;109:701-705.

36. Hillen U, Haude M, Erbel R, Goos M. Evaluation of metal allergies in patients with coronary stents. Contact Dermatitis. 2002;47:353-356.

37. Moses JW, Leon MB, Popma JJ, et al. Sirolimus-eluting stents versus standard stents in patients with stenosis in a native coronary artery. N Engl J Med. 2003;349:1315-1323.

38. Stone GW, Ellis SG, Cox DA, et al. One-year clinical results with the slow-release, polymer-based, paclitaxel-eluting TAXUS stent: the TAXUS-IV trial. Circulation. 2004;109:1942-1947.

39. Aliağaoğlu C, Turan H, Erden I, et al. Relation of nickel allergy with in-stent restenosis in patients treated with cobalt chromium stents. Ann Dermatol. 2012;24:4.

40. Svedman C, Tillman C, Gustavsson CG, Moller H, Frennby B, Bruze M. Contact allergy to gold in patients with gold-plated intracoronary stents. Contact Dermatitis. 2005;52:192-196.

41. Svedman C, Lundh T, Tillman C, Moller H, Gustavsson CG, Bruze M. Gold concentration in blood in patients with gold-plated stents. Contact Dermatitis. 2006;54:221-222.
42. Saito T, Hokimoto S, Oshima S, Noda K, Kojyo Y, Matsunaga K. Metal allergic reaction in chronic refractory in-stent restenosis. Cardiovasc Revasc Med. 2009;10:17-22.

43. Chioncel V, Brezeanu R, Sinescu C. New directions in the management of peripheral artery disease. Am J Ther. 2019;26(2):e284-e293.

44. Guntani A, Kawakubo E, Ryosuke Yoshiga R, et al. Metallic allergy requiring removal of iliac stent: report of a case. Surg Case Rep. 2020;6:82.

45. Khodaverdian RA, Jones KW. Metal allergy to Amplatzer occlude device presented as severe bronchospasm. Ann Thorac Surg. 2009;88:2021-2022.

46. Slavin L, Tobis JM, Rangarajan K, Dao C, Krivokapich J, Liebeskind DS. Five-year experience with percutaneous closure of patent foramen ovale. Am J Cardiol. 2007;99:1316-1320.

47. Norgaz T, Hobikoglu G, Serdar ZA, et al. Is there a link between nickel allergy and coronary stent restenosis? Tohoku J Exp Med. 2005;206:243-246.

48. Thyssen JP, Engkilde K, Menne T, Johansen JD, Hansen PR, Gislason GH. No association between metal allergy and cardiac in-stent restenosis in patients with dermatitis-results from a linkage study. Contact Dermatitis. 2011;64:138-141.

49. Slodownik C, Danenberg C, Merkin D, et al. Coronary stent restenosis and the association with allergy to metal content of $316 \mathrm{~L}$ stainless steel. Cardiovasc J Afr. 2018;29:43-45.

50. Romero-Brufau S, Best PJM, Holmes DR, et al. Outcomes after coronary stent implantation in patients with metal allergy. Circ Cardiovasc Interv. 2012;5:220-226.

51. Virmani R, Kolodgie FD, Farb A. Drug-eluting stents: are they really safe? Am Heart Hosp J. 2004;2(2):85-88.

52. Nebeker R, Virmani C, Bennett L, et al. Hypersensitivity cases associated with drug-eluting coronary stents: a review of available cases from the Research on Adverse Drug Events and Reports (RADAR) project. J Am Coll Cardiol. 2006;47(1):175-181.

53. Farb A, Burke AP, Kolodgie FD, Virmani R. Pathological mechanisms of fatal late coronary stent thrombosis in humans. Circulation. 2003;108(14):1701-1706.

54. van Alst M, Eenink MJD, Kruft MAB, Van Tuil R. ABC's of bioabsorption: application of lactide based polymers in fully resorbable cardiovascular stents. EuroIntervention. 2009;5:F23-F27.

55. Ceonzo K, Gaynor A, Shaffe L, Kojima K, Vacanti CA, Stahl GL. Polyglycolic acid-induced inflammation: role of hydrolysis and resulting complement activation. Tissue Eng. 2006;12 (2):301-308

56. Serruys PW, Kukreja N. Late stent thrombosis in drug eluting stents: return of the 'VB syndrome'. Nat Clin Pract Cardiovasc Med. 2006;3 (12):637.

57. Ong AT, Serruys PW. Technology insight: an overview of research in drug-eluting stents. Nat Clin Pract Cardiovasc Med. 2005;2 (12):647-658.

58. Patel MJ, Patel SS, Patel NS, Patel NM. Current status and future prospects of drug eluting stents for restenosis. Acta Pharmaceutica. 2012;62(4):473-496.

59. Navarese EP, Kowalewski M, Cortese B, et al. Short and long term safety and efficacy of polymer-free vs. durable polymer drug-eluting stents.A comprehensive meta-analysis of randomized trials including 6178 patients. Atherosclerosis. 2014;233(1):224-231.

60. Campos CM, Muramatsu T, Iqbal J, et al. Bioresorbable drug-eluting magnesium-alloy scaffold for treatment of coronary artery disease. Int J Mol Sci. 2013;14(12):24492-24500.

61. Smith EJ, Jain AK, Rothman MT. New developments in coronary stent technology. J Interv Cardiol. 2006;19(6):493-499.

62. Joner M, Finn AV, Farb A, et al. Pathology of drug-eluting stents in humans: delayed healing and late thrombotic risk. J Am Coll Cardiol. 2006;48:193-202. 
63. Nguyen SH, Dang TP, MacPherson C, Maibach H, Maibach HI. Prevalence of patch test results from 1970 to 2002 in a multi-centre population in North America (NACDG). Contact Dermatitis. 2008;58:101-106.

64. Minai-Fleminger Y, Levi-Schaffer F. Mast cells and eosinophils: the two key effector cells in allergic inflammation. Inflamm Res. 2009;58: e631-e638.

65. Wataha JC, O’Dell NL, Singh BB, Ghazi M, Whitford GM, Lockwood PE. Relating nickel-induced tissue inflammation to nickel release in vivo. J Biomed Mater Res. 2001;58:537-544.

66. Nakazawa G, Otsuka F, Nakano M, et al. The pathology of neoatherosclerosis in human coronary implants bare-metal and drug-eluting stents. J Am Coll Cardiol. 2011;57:1314-1322.

67. Farb A, Sangiorgi G, Carter AJ, et al. Pathology of acute and chronic coronary stenting in humans. Circulation. 1999;99:44-52.

68. Ribichini F, Tomai F, De Luca G, et al. Immunosuppressive therapy with oral prednisone to prevent restenosis after PCI. A multicenter randomized trial. Am J Med. 2011;124:434-443.

69. Rhen T, Cidlowski JA. Antiinflammatory action of glucocorticoidsnew mechanisms for old drugs. N Engl J Med. 2005;353:1711-1723.

70. Chioncel V, Avram A, Sinescu C. A particular case of Wellens' syndrome. Med Hypotheses. 2020;144:110013.

71. Konishi T, Yamamoto T, Funayama T, et al. Stent thrombosis caused by metal allergy complicated by protein $\mathrm{S}$ deficiency and heparin-induced thrombocytopenia: a case report and review of the literature. Thromb J. 2015;13:25.

72. Tatu AL, Baroiu L, Fotea S, et al. A working hypothesis on vesicular lesions related to COVID-19 infection, Koebner Phenomena Type V, and a short review of related data. Clin Cosmet Investig Dermatol. $2021 ; 14: 419-423$.

73. Verheye S, Ormiston JA, Stewart J, et al. A next-generation bioresorbable coronary scaffold system: from bench to first clinical evaluation: 6- and 12-month clinical and multimodality imaging results. JACC Cardiovasc Interv. 2014;7:89-99.

74. Sciatti E, Vizzardi E, Cani DS, et al. Kounis syndrome, a disease to know: case report and review of the literature. Monaldi Arch Chest Dis. 2018;88:898.
75. Kounis NG. Coronary hypersensitivity disorder: the Kounis syndrome. Clin Ther. 2013;35:563-571.

76. Tzanis G, Bonou M, Mikos N, et al. Early stent thrombosis secondary to food allergic reaction: kounis syndrome following rice pudding ingestion. World J Cardiol. 2017;9:283-288.

77. Tripolino C, Tassone EJ, Morabito G, Grillo P, Missiroli B. Acute coronary stent thrombosis: a case of type 3 Kounis syndrome. J Cardiol Cases. 2019;19:33-35.

78. Michas G, Stougiannos P, Thomopoulos T, et al. Acute anterior myocardial infarction due to stent thrombosis after mushroom consumption: a case of Kounis type III syndrome. Hellenic J Cardiol. 2017;58:378-380

79. Tatu AL, Ionescu MA. Multiple autoimmune syndrome type III thyroiditis, vitiligo and alopecia areata. Acta Endo (Buc). 2017;13 (1):124-125.

80. Seabra-Gomes R. Percutaneous coronary interventions with drug eluting stents for diabetic patients. Heart. 2006;92(3):410-419.

81. Gilbert J, Raboud J, Zinman B. Meta-analysis of the effect of diabetes on restenosis rates among patients receiving coronary angioplasty stenting. Diabetes Care. 2004;27:990-994.

82. Machecourt J, Danchin N, Lablanche JM, et al. Risk factors for stent thrombosis after implantation of sirolimus-eluting stents in diabetic and nondiabetic patients: the EVASTENT matched-cohort registry. J Am Coll Cardiol. 2007;50(6-7):501-508.

83. Kern M. How should we manage nickel allergy in patients needing coronary stents? Cathlabdigest. 2011;19:1.

84. Tatu AL, Elisei AM, Chioncel V, Miulescu M, Nwabudike LC. Immunologic adverse reactions of $\beta$-blockers and the skin. Exp Ther Med. 2019;18(2):955-959.

85. Kounis NG, Mazarakis A, Tsigkas G. Giannopoulos S and Goudevenos J. Kounis syndrome: a new twist on an old disease. Future Cardiol. 2011;7:e805-e824.
International Journal of General Medicine

\section{Publish your work in this journal}

The International Journal of General Medicine is an international, peer-reviewed open-access journal that focuses on general and internal medicine, pathogenesis, epidemiology, diagnosis, monitoring and treatment protocols. The journal is characterized by the rapid reporting of reviews, original research and clinical studies

\section{Dovepress}

across all disease areas. The manuscript management system is completely online and includes a very quick and fair peer-review system, which is all easy to use. Visit http://www.dovepress.com testimonials.php to read real quotes from published authors. 